\title{
Propagation of a Crack in a Composite Plate
}

\author{
IONEL IACOB *, IONEL CHIRICA, ELENA FELICIA BEZNEA \\ Dunarea de Jos University of Galati, Faculty of Engineering, 47 Domneasca Str., 800008, Galati, Romania
}

\begin{abstract}
In this paper, a model of a composite plate with a central elliptical cut-out and with an initial fissure was subjected to a tension load in the finite element method (FEM) software Abaqus to observe the propagation of that crack during a certain amount of time that elapsed in the FEM analysis. Due to symmetry, only half of the plate was modeled, as a shell, and the extended finite element method (XFEM) was used for the crack. The material properties that were assigned to the plate were taken from the database of the Ansys Mechanical software. In the vicinity of the crack a finer mesh was applied to be able to better observe the evolution of the fissure and the changes of the Von Misses stress graphs for each time step of the analysis.
\end{abstract}

Keywords: Crack Propagation, Abaqus, XFEM, Composite Plate

For designing and fabricating a strong, resistant composite material, that doesn't break very easily, an important factor that is necessary to be analyzed is how cracks form and propagate in different combinations of materials, based on their purpose. The propagation of the cracks can be influenced by some fabrication flaws, for example there can be flaws related to the fibers, matrix porosity, interfacial porosity, etc. The existence of these flaws can reduce the durability of the material, the cracks propagating faster and easier [1].

Because cracks are one of the possible defects that can appear in composite materials, there is an interest in simulating the propagation of these cracks, to be able to predict the initiation of a crack, in which direction it will propagate, how much time it takes until a structure made from a certain composite breaks due to cracking, etc. [2]

There have been multiple studies that have analyzed different aspects of crack propagation, under different types of loading cases.

Some researchers [3-5] studied the fracture behavior of composites under static loading conditions, this being a simplification of what happens in reality, when there are more complex, dynamic loading cases [2].

There are also numerous studies on the behavior of cracks in composite materials subjected to dynamic loadings [6-8] and fatigue loading cases $[9,10]$.

In 1999, Ted Belytschko created the extended finite element method (XFEM) [11]. Multiple crack propagation studies $[2,12,13]$ have used this method, since then, for some of its advantages when it comes to meshing models with fractures. In the last decade the various meshing methods have been used for the modelling of multilayered polymeric composites, like in [14, 15], where so static and dynamic analysis is studied.

\section{Experimental part \\ Model description}

In this paper an epoxy-glass composite plate with a central cut-out was analyzed using the Abaqus software. The dimensions of the plate (fig. 1) were $3000 \mathrm{~mm}$ length, $2000 \mathrm{~mm}$ width and the central elliptical cut-out had 1500 $\mathrm{mm}$ total length with a radius of $500 \mathrm{~mm}$ at each end. An initial crack of $150 \mathrm{~mm}$ was also modeled for the extended finite element method. Only half of the plate was modeled, with symmetry conditions.

The following boundary conditions have been applied to the model (fig. 2):

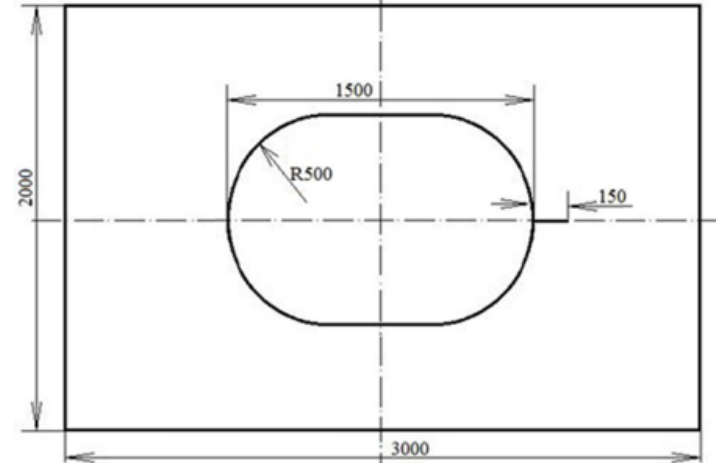

Fig. 1. The geometry of the plate with a central elliptical cut-out and a crack (dimensions in $\mathrm{mm}$ )

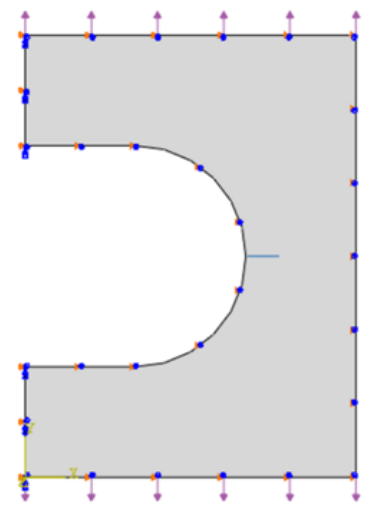

Fig. 2. The boundary conditions

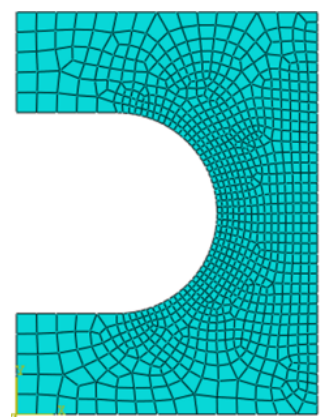

Fig. 3. The mesh used for the analysis

and the tension pressures

applied to the analyzed model

-the translation on the $x$ axis and the rotation around the $z$ axis were blocked on the contour of the model

-symmetry conditions for the other half of the plate

On the top and bottom contour lines of the shell model tension pressures of $100-500 \mathrm{MPa}$ were applied.

A quadrilateral mesh was used (fig. 3), with an approximate global size of 100 millimeters. Around the crack and also on the right contour line, more elements were applied. This was done so that the difference in size of the elements wasn't very big in the vicinity of the crack and to improve the accuracy of the results.

\section{Results and discussions \\ FEM analysis}

After the maximum number of increments (1000) and the increment size (initial 0.02; minimum 1e-007; maximum 1) have been set, a static analysis was run. The

\footnotetext{
* email: ionel.iacob@ugal.ro
} 


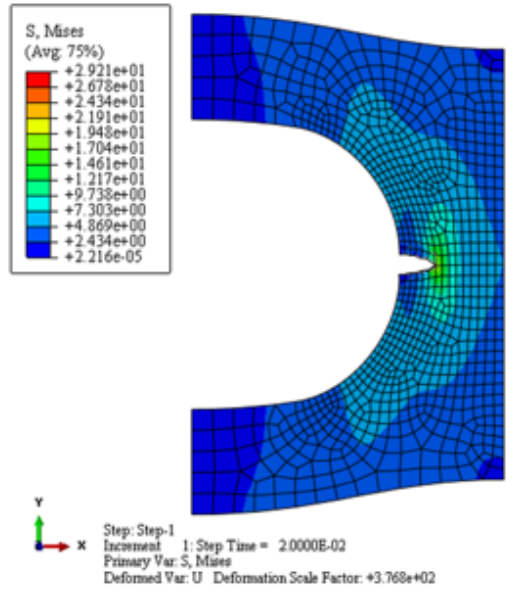

Fig. 4. The Von Misses stresses [MPa] for the first increment of the analysis for an applied tension pressure of $100 \mathrm{MPa}$

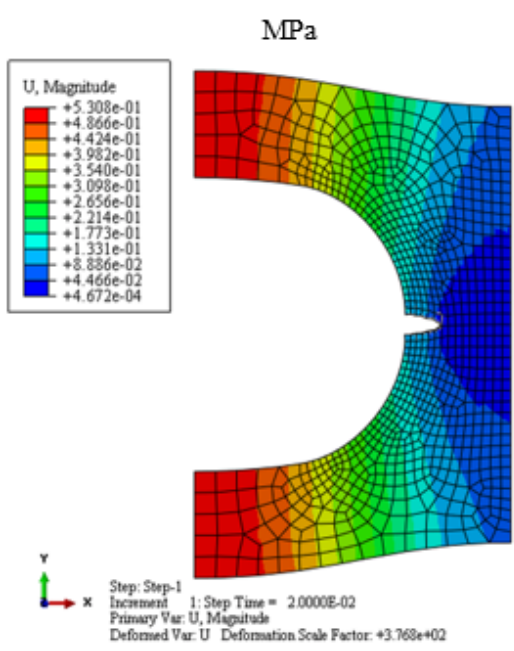

Fig 6. The displacement values [ $\mathrm{mm}$ ] for the first increment of the analysis for an applied tension pressure of $100 \mathrm{MPa}$

$\mathrm{MPa}$

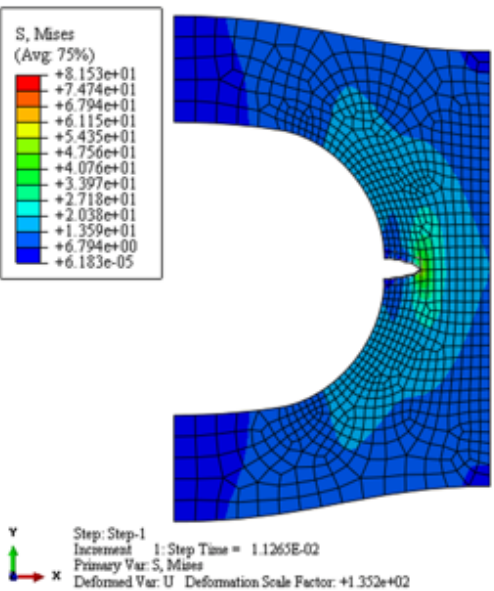

Fig. 8.The Von Misses stresses [MPa] for the first increment of the analysis for an applied tension pressure of $500 \mathrm{MPa}$

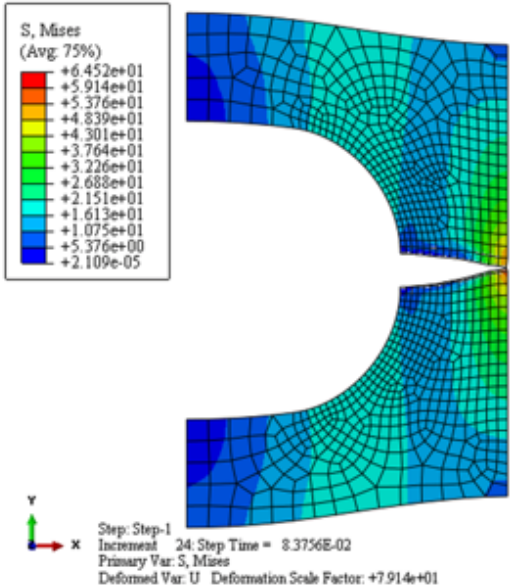

Fig. 5. The Von Misses stresses [MPa] for the increment of the analysis when the plate model breaks, for an applied tension pressure of $100 \mathrm{MPa}$

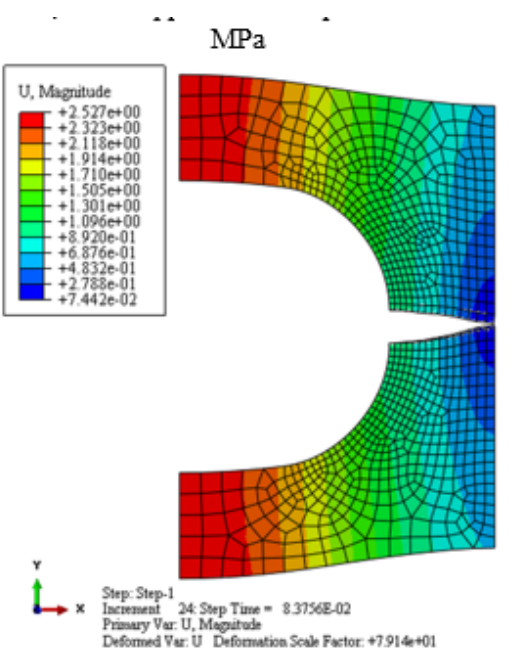

Fig. 7. The displacement values [mm] for the increment of the analysis when the plate model breaks, for an applied tension pressure of $100 \mathrm{MPa}$

$\mathrm{MPa}$

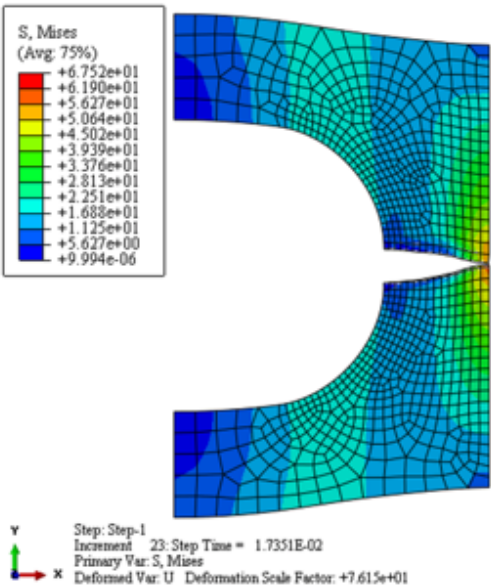

Fig. 9. The Von Misses stresses [MPa] for the increment of the analysis when the plate model breaks, for an applied tension pressure of $500 \mathrm{MPa}$ 

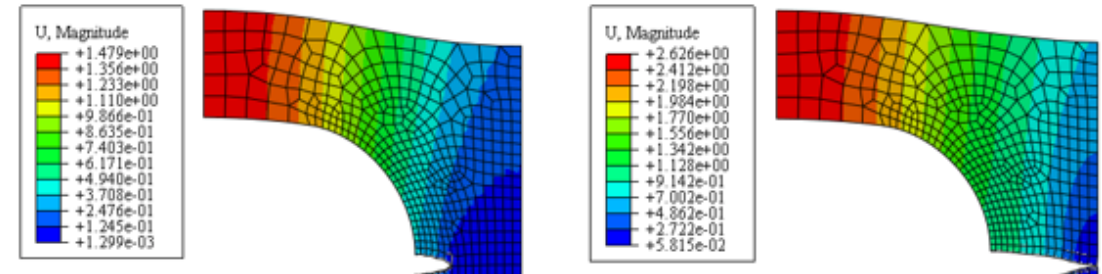

Fig. 11. The

displacement values

Fig. 10. The displacement values [mm] for the first increment of the analysis for an applied tension pressure of $500 \mathrm{MPa}$

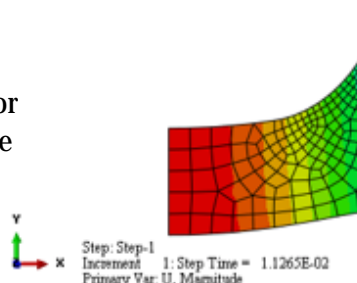

Primary Par. U., Meguitude
Deformed Viar U Deformation Seshe Fator $+13530+02$

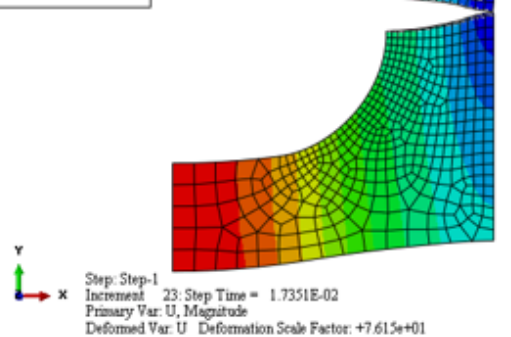

[mm] for the increment of the analysis when the plate model breaks, for an applied tension pressure of $500 \mathrm{MPa}$

\begin{tabular}{|c|c|c|c|c|c|}
\hline $\begin{array}{l}\text { Incre } \\
\text { ment }\end{array}$ & $\begin{array}{c}\text { The Von Misses } \\
\text { stresses for the } \\
\text { 100MPa pressure } \\
\text { case [MPa] }\end{array}$ & $\begin{array}{l}\text { The Von Misses } \\
\text { stresses for the } \\
\text { 200MPa pressure } \\
\text { case [MPa] }\end{array}$ & $\begin{array}{l}\text { The Von Misses } \\
\text { stresses for the } \\
\text { 300MPa pressure } \\
\text { case [MPa] }\end{array}$ & $\begin{array}{l}\text { The Von Misses } \\
\text { stresses for the } \\
\text { 400MPa pressure } \\
\text { case [MPa] }\end{array}$ & $\begin{array}{l}\text { The Von Misses } \\
\text { stresses for the } \\
\text { 500MPa pressure } \\
\text { case [MPa] }\end{array}$ \\
\hline 0 & 0 & 0 & 0 & 0 & 0 \\
\hline 1 & 29.21 & 58.43 & 82.21 & 81.87 & 81.53 \\
\hline 2 & 58.86 & 75.63 & 86.37 & 86.15 & 85.93 \\
\hline 3 & 74.3 & 84.49 & 62.34 & 62.09 & 61.86 \\
\hline 4 & 82.87 & 70.32 & 73.92 & 73.86 & 73.8 \\
\hline 5 & 68.55 & 72.88 & 65.69 & 65.67 & 65.66 \\
\hline 6 & 71.12 & 56.54 & 67.43 & 67.44 & 67.46 \\
\hline 7 & 55.39 & 58.19 & 71.14 & 70.59 & 70.13 \\
\hline 8 & 57.51 & 65.9 & 66.43 & 66.01 & 65.64 \\
\hline 9 & 65.45 & 64.79 & 58.81 & 58.08 & 57.57 \\
\hline 10 & 70.87 & 67.86 & 63.37 & 63.73 & 61.52 \\
\hline 11 & 67.61 & 58.32 & 57.87 & 62.18 & 63.02 \\
\hline 12 & 65.85 & 62.83 & 62.66 & 55.36 & 63.2 \\
\hline 13 & 57.82 & 63.86 & 63.54 & 62.11 & 58.72 \\
\hline 14 & 64.66 & 62.89 & 57.5 & 64.07 & 59.97 \\
\hline 15 & 56.17 & 59.05 & 59.3 & 59.06 & 62.14 \\
\hline 16 & 61.46 & 59.99 & 54.67 & 60.24 & 57.12 \\
\hline 17 & 55.21 & 54.66 & 56.37 & 55.18 & 58.65 \\
\hline 18 & 59.61 & 57.61 & 58.47 & 58.7 & 58.88 \\
\hline 19 & 61.88 & 58.53 & 60.3 & 59.2 & 55.07 \\
\hline 20 & 57.08 & 60.37 & 55.5 & 55.02 & 56.82 \\
\hline 21 & 60.07 & 56.87 & 55.57 & 55.68 & 58.61 \\
\hline 22 & 56.82 & 57.74 & 57.74 & 56.8 & 66.2 \\
\hline 23 & 59.99 & 60.96 & 58.12 & 57.59 & 67.52 \\
\hline 24 & 64.52 & 66.78 & 58.84 & 60.79 & - \\
\hline 25 & - & 68.72 & 64.17 & 65.82 & - \\
\hline 26 & - & 71.06 & 65.45 & 67.66 & - \\
\hline 27 & - & - & 67.37 & 70.26 & - \\
\hline 28 & - & - & 68.52 & 71.26 & - \\
\hline
\end{tabular}

Table 1

THE VON MISSES STRESSES FOR THE ANALYZED PRESSURE CASES

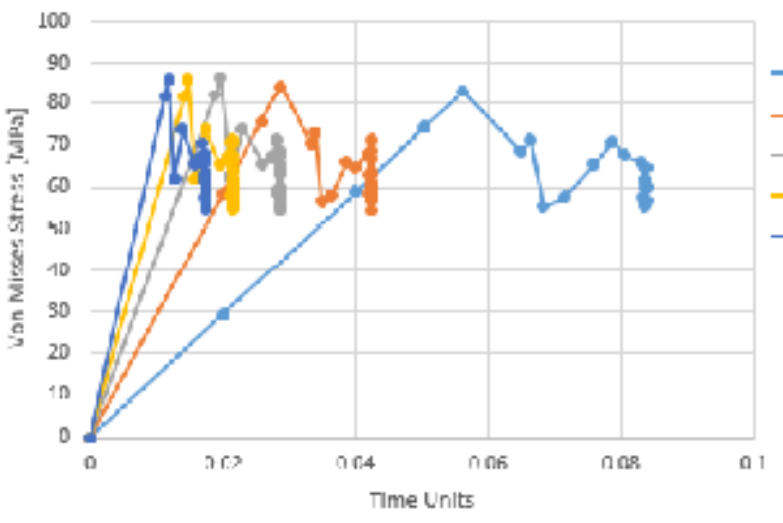

Fig. 12. The variation of the maximum Von Misses stress values in time for the analyzed tension pressures cases that were applied

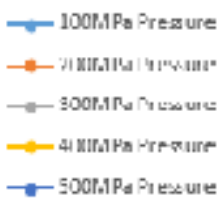

results that were observed were, mainly, the effects that the propagation of the crack had on the Von Misses stresses and the displacements of the plate, until the breaking moment occurs. In the following figures, the starting and the breaking increments for the $100 \mathrm{MPa}$ pressure cases are presented. The rest of the results are presented in the tables 1, 2 and the diagrams 12, 13. 


\begin{tabular}{|c|c|c|c|c|c|c|}
\hline $\begin{array}{l}\text { Incre } \\
\text { ment }\end{array}$ & $\begin{array}{c}\text { Displacement } \\
\text { values for the } \\
\text { 100MPa pressure } \\
\text { case [mm] }\end{array}$ & $\begin{array}{c}\text { Displacement } \\
\text { values for the } \\
\text { 200MPa pressure } \\
\text { case [mm] }\end{array}$ & $\begin{array}{c}\text { Displacement } \\
\text { values for the } \\
\text { 300MPa pressure } \\
\text { case [mm] }\end{array}$ & $\begin{array}{c}\text { Displacement } \\
\text { values for the } \\
400 \mathrm{MPa} \text { pressure } \\
\text { case [mm] }\end{array}$ & $\begin{array}{c}\text { Displacement } \\
\text { values for the } \\
\text { 500MPa pressure } \\
\text { case [mm] }\end{array}$ & \multirow{30}{*}{$\begin{array}{c}\text { Table } 2 \\
\text { THE DISPLACEMENT } \\
\text { VALUES FOR THE } \\
\text { ANALYZED } \\
\text { PRESSURE CASES }\end{array}$} \\
\hline 0 & 0 & 0 & 0 & 0 & 0 & \\
\hline 1 & 0.5308 & 1.062 & 1.494 & 1.486 & 1.479 & \\
\hline 2 & 1.072 & 1.378 & 1.574 & 1.572 & 1.569 & \\
\hline 3 & 1.352 & 1.539 & 1.718 & 1.716 & 1.714 & \\
\hline 4 & 1.508 & 1.825 & 1.891 & 1.891 & 1.89 & \\
\hline 5 & 1.786 & 1.864 & 2.17 & 2.17 & 2.17 & \\
\hline 6 & 1.825 & 1.931 & 2.296 & 2.297 & 2.298 & \\
\hline 7 & 1.895 & 2.021 & 2.405 & 2.403 & 2.402 & \\
\hline 8 & 1.988 & 2.154 & 2.422 & 2.421 & 2.42 & \\
\hline 9 & 2.125 & 2.236 & 2.468 & 2.462 & 2.458 & \\
\hline 10 & 2.21 & 2.409 & 2.497 & 2.491 & 2.487 & \\
\hline 11 & 2.261 & 2.437 & 2.512 & 2.497 & 2.506 & \\
\hline 12 & 2.387 & 2.46 & 2.524 & 2.508 & 2.553 & \\
\hline 13 & 2.415 & 2.475 & 2.533 & 2.528 & 2.579 & \\
\hline 14 & 2.462 & 2.512 & 2.549 & 2.541 & 2.583 & \\
\hline 15 & 2.468 & 2.532 & 2.56 & 2.569 & 2.59 & \\
\hline 16 & 2.483 & 2.536 & 2.568 & 2.573 & 2.602 & \\
\hline 17 & 2.492 & 2.542 & 2.574 & 2.58 & 2.61 & \\
\hline 18 & 2.499 & 2.551 & 2.578 & 2.592 & 2.612 & \\
\hline 19 & 2.504 & 2.553 & 2.581 & 2.594 & 2.615 & \\
\hline 20 & 2.512 & 2.556 & 2.582 & 2.598 & 2.619 & \\
\hline 21 & 2.517 & 2.56 & 2.584 & 2.6 & 2.622 & \\
\hline 22 & 2.521 & 2.562 & 2.587 & 2.602 & 2.624 & \\
\hline 23 & 2.524 & 2.564 & 2.587 & 2.603 & 2.626 & \\
\hline 24 & 2.527 & 2.565 & 2.588 & 2.604 & - & \\
\hline 25 & - & 2.566 & 2.588 & 2.605 & - & \\
\hline 26 & - & 2.567 & 2.589 & 2.605 & - & \\
\hline 27 & - & - & 2.59 & 2.607 & - & \\
\hline 28 & - & - & 2.591 & 2.607 & - & \\
\hline
\end{tabular}

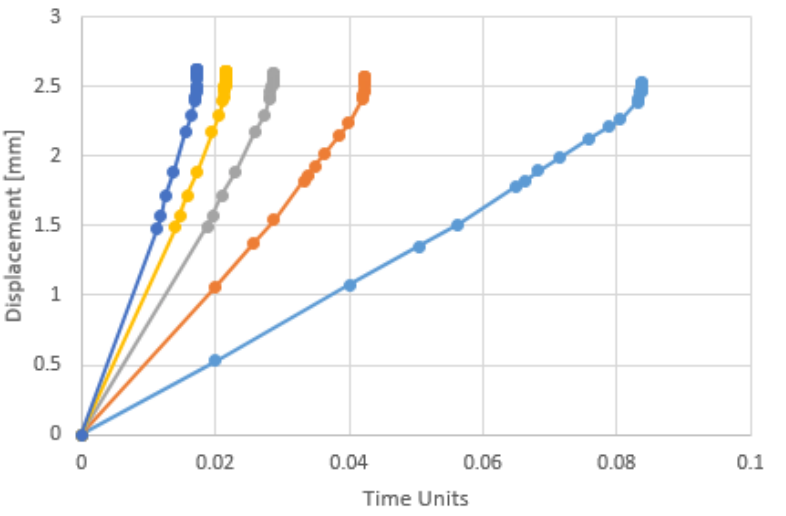

The results obtained from Abaqus are gathered in the tables 1 and 2 and the diagrams from figures 12 and 13 .

\section{Conclusions}

The analysis using the FEM software Abaqus of an epoxyglass composite plate with a central elliptical cut-out and an initial crack was presented in this paper. Only half of the plate was modeled, due to symmetry, with contour constraints and five tension pressure cases were applied to two of the plate's edges. The main results that were observed were the variation of the Von Misses stress and the evolution of the displacement values in a certain amount of time that was needed for the initial crack to propagate until the break of the plate.

By analyzing the tables and the graphs it can be observed that the Von Misses stresses, for all pressure cases, have an initial linear increase until the initial crack visibly opens more than the length it had until then, due to the tension pressures, then there is a decrease, until the crack starts opening more, when another stress increase can be seen;
Fig. 13. The variation of the maximum displacement values in time for the analyzed tension pressures cases that were applied 
3. FIEDLER, B., HOJ O, M., OCHIAI, S., SCHULTE, K., ANDO, M., Failure behavior of an epoxy matrix under different kinds of static loading. Composites Science and Technology, 61(11), 1615-1624

4. LIU, S., NAIRN, J. A., The formation and propagation of matrix microcracks in cross-ply laminates during static loading. Journal of reinforced plastics and composites, 11(2), 158-178

5.ZWEBEN, C., Tensile failure of fiber composites. AIAA journal, 6(12), 2325-2331

6. THEOCARIS, P. S., MILIOS, J., Dynamic crack propagation in composites. International J ournal of Fracture, 16(1), 31-51

7.WANG, B. L., HAN, J. C., DU, S. Y., Cracks problem for nonhomogeneous composite material subjected to dynamic loading. International Journal of Solids and Structures, 37(9), 12511274

8.MAMALIS, A. G., MANOLAKOS, D. E., IOANNIDIS, M. B., PAPAPOSTOLOU, D. P., On the response of thin-walled CFRP composite tubular components subjected to static and dynamic axial compressive loading: experimental. Composite structures, 69(4), 407420

9. GASSAN, J., A study of fibre and interface parameters affecting the fatigue behaviour of natural fibre composites. Composites part $A$ : applied science and manufacturing, 33(3), 369-374
10. DAUSKARDT, R. H., DALGLEISH, B. J., YAO, D., RITCHIE, R. O., BECHER, P. F., Cyclic fatigue-crack propagation in a silicon carbide whisker-reinforced alumina composite: role of load ratio. J ournal of materials science, 28(12), 3258-3266

11. MOES, N., DOLBOW, J., BELYTSCHKO, T., A finite element method for crack growth without remeshing. International Journal for Numerical Methods in Engineering. 46 (1), 131-150

12. YE, C., SHI, J., CHENG, G. J., An Extended Finite Element Method (XFEM) study on the effect of reinforcing particles on the crack propagation behavior in a metal-matrix composite. International Journal of Fatigue, 44, 151-156

13. HUYNH, D. B. P., BELYTSCHKO, T., The extended finite element method for fracture in composite materials. International J ournal for Numerical Methods in Engineering, 77(2), 214-239

14. ZGIRIAN, G., DEMETRESCU, I., GHEORGHIU, H., IOVU, H., HADAR, A., ATANASIU, C., The modelling of some polymeric compounds: from synthesis to mechanical properties and finite elements calculation. Rev. Chim. (Bucharest), 56, no. 7, 2005, p. 757

15. CORMOS, R., PETRESCU, H., HADAR, A., ADIR, G.M., GHEORGHIU, $\mathrm{H}$., Finite Element Analysis of the Multilayered Honeycomb Composite Material Subjected to Impact Loading, Mat. Plast. 54, no. 1, 2018, p. 180

Manuscript received: 23.11.2017 